\section{Women and depression}

\author{
Kharel B \\ Intern, Kathmandu Medical College, Sinamangal, Nepal
}

$\mathrm{B}$ eing a medical student during those four and half years of my MBBS studies I have come across quite a few diseases. Talking about the gender predominance of the diseases, I have seen that most of the diseases had a female preponderance. Each and every disease has its own aetiopathogenesis which might provide a scientific explanation about its greater tilt towards the female gender. However, in this article, I would like to share my opinion over the predominance of the mental illness in women.

During my Internship in Medicine, Psychiatry and Emergency, I encountered quite a lot of female patients suffering from one or the other diseases. Some of them had psychiatric illness with a concurrent medical disease and many of them were the sufferers of a sole psychiatric illness presenting as a misinterpreted symptoms of medical illness. Depression was in fact the most frequently encountered case among the psychiatric illnesses, wherein the common stress factors were family conflicts, tragic events, unemployment and physical / emotional trauma. Leaving behind the genetic and biochemical theories, here I would be dealing with the social and environmental factors aggravating the incidence of depression in women.

The classical symptoms of patient with depression are prolonged sadness, loss of an ability to enjoy pleasure, increased fatigability, helplessness, hopelessness and worthlessness. However, patients usually reveal these typical features only after prolonged interrogation and series of direct and indirect questions. Most of the depressed women present with somatic symptoms as chest pain, palpitation, fearfulness, headache, and feeling of something in the throat (FOSIT), burning/ tingling sensation of abdomen / whole body, shortness of breath and in extreme cases with suicidal tendencies ${ }^{1}$.

Almost everyone suffering from depression has some or the other inducing stress factors. As mentioned earlier, the most common stress factor would be family conflicts, emotional/financial and tragic events, loneliness, unemployment and extramarital affairs which are becoming more prevalent now-a-days. A doctor senior once told me that females living in this part of the world who face such negative consequences are more likely to present with depressive features, while the same stress factors would lead women in developed country to come in psychiatry clinic with features of substance and alcohol dependence. Ours is a male dominated country where women are laid back in some or the other way. Comparatively, females are still far away from the light of literature and even our women are not as much extrovert to open up themselves. They still hesitate to stand up and raise their voice against the assaults and insults they are going through. On addition to that, there lies the pre-existing emotional fragility and lack of freedom.

\section{Common Inducing factors of depression among women}

1. Discrimination between male and female gender

2. Loneliness among women

3. Tragic events

4. Family pressure

5. Extra marital affairs

\section{Discrimination between male and female gender}

We, living in a literate, understanding family, are fortunately lucky, but majority of women in our part of the world are still experiencing some kind of discrimination against females. Not only better foods--better education and better opportunities for employment, even better attention and love is offered to the male members of the family. The left out environment and restriction to freedom of speech causes burial of one's feelings within oneself. This could break out the limitation of tolerance at one extreme point of time resulting in an outburst. Such emotional outburst is one of the leading causative factors for the initiation of depressive disorder.

\section{Loneliness among women}

In our part of the world, women are still devoid of opportunities when it comes to working outside

\footnotetext{
Correspondence

Dr. Binita Kharel

Intern,

Kathmandu Medical College,

Sinamangal, Nepal

E-mail: beennita3@hotmail.com
} 
the home. As such, they are not able to utilize their knowledge in the work even if they are educated. The rooted belief that women are only supposed to stay at home looking after the family and domestic matters instead of working outside the four walls acts as an inducer to de-socialisation. The common causes of loneliness in women eventually leading to depressive symptoms could be:

a. Husband working abroad,

b. Left alone at the home, devoid of touch with reality, and away from the outer world limited within the four walls of the room and television as the only friends,

c. Housewife of working family members not engaged in any work to keep herself busy,

d. Hesitancy to share the personal problems with friends and other people around due to fear of going against the so called "social and familial norms".

\section{Tragic event}

Tragic event in the life as loss or death of a beloved person or a downfall in financial matters has always been a common inducer. Though tragic events can cause depression in both men and women, it seems to have more impact on women, more likely due to emotional fragility and lack of communication in women as compared to men.

\section{Extra marital affairs}

Other emerging cause of depression seen in today's so called "modernised" $21^{\text {st }}$ century world where "Extra Marital Affairs" are more into materialisation and lack of loyalty and faithfulness among the partners is spreading around. Women are the sufferers in this matter as well because men are thought to be involved in such affairs more in comparison to women.

\section{Family pressure}

Family pressure leading to compelled choice of occupation, opportunity in further studies and lack of concern towards the actual interest of the women and children is very common. Applicable to both genders, this may lead to fear of poor performance in the exams which can be a cause of depressive disorder among young people.

Mental pressure and emotional torture by the in-laws, especially in the matters of dowry and childbirth, is also very much common among women in our country, acting as one of the inducer of depressionCan those inducing factors be minimized, controlled and avoided?

Yes! It surely can. It surely can if people are made aware of the fact by educating them and if they are taught to cope up with the problems in a positive manner.
Nepal is a country full of different cultures and traditions but when it comes to mental illness, concept related to it is more or less common in all the cultures. In our country, most of the people think that suffering from mental illness is to become mad or lunatic, being unfit to stay in the society and family due to loss of control over self and sometimes to become possessed by a holy spirit or a black magic. Hence, in our context, our first attempt should be to make the people understand that depression and/ or all the psychiatric disorders don't mean being "mad or maniac". It is like any other illness e.g. Jaundice and diabetes, which has medicines available and which can be treated, the only difference being that it also has psychotherapy and counselling added to just "medicines". Then after, educating the people about the avoidance of causative factors and teaching them about the problem facing skills in different steps of life would be essential.

A better approach towards educating the people in matters of mental ill health should be seeked for. Social discrimination towards the mental ill health sufferers should be controlled and personal liberty along with avoidance of unfair and unjust behaviour should be insured. They should be provided with better opportunities in various walks of life.

Mental ill health is still not much talked about because of the stigma attached ${ }^{2}$. Hence, attempts should be made to make people aware about the misinterpretation and false beliefs towards mental ill health. The obstacles to get benefit of mental health services including poverty, stigmatization, and a lack of awareness and services should be minimized as far as possible. The family member involved in the treatment of those patient should be informed well that the cost of medicines in such cases may not be very high if the qualified specialist is reached at the proper time as most of the patient come to the psychiatric clinic after investment of lots of time and money on the "so called" local healers.

On addition to that, help and support along with concern from the government is equally important to improve the status of mental ill health sufferers. Less than $3 \%$ of the national budget is allocated to the health sector out of which mental health receives insignificant attention with allotment of $1 \%$ of the health budget on mental health ${ }^{3}$. There is no mental health act ${ }^{4,5}$ and the National Mental Health Policy formulated in 1997 is yet to be fully operational and on addition to that, adequate manpower is not available when it comes to mental health.

Data and surveys in these areas are relatively lacking far behind. There are no national data on the disorderspecific prevalence of mental illness either-in the 
general population or in primary or secondary care. A study by Shrestha et al., in 1983 did suggest that about $10 \%$ of the population of a district community needed help for mental problems at that time ${ }^{5,6}$. Hence, proposals should be made and implemented on doing research and collecting data on those conditions.

\section{Conclusions}

The main laid back points for mental health in Nepal are the lack of adequate manpower, unaware public and absence of formulation and implementation of an adequate policy. To improve mental health care access in Nepal, efforts should be focused on raising awareness, giving proper and adequate information, making existing services available to the general public and the proper monitoring of mental health delivery systems ${ }^{7}$. However, here, as we are considering the interrelationship between Nepali women and depression ; we are more concerned on upliftment of women empowerment (physical and mental ), helping them take full benefits of democracy and modernization, that would surely at some point of time decrease the incidence of women mental ill health.

\section{References}

1. Wright C, Nepal MK, Bruce-Jones WDA. Mental health patients in primary health care services in Nepal. Asia-Pacific Journal of Public Health. 1989; 3:3.224-30.

2. Acharya K. Knowledge, attitude and practice of mental illness in a village population; Tribhuvan University Kathmandu Nepal. Thesis submitted to the Department of Sociology and Anthropology. Kathmandu: TU; 1998.
3. Shrestha NM. Present status, policy and programmes on mental health in Nepal KathmanduNepal. Paper presented during a function organized to celebrate Mental Health Day 2001. (in Nepalese)

4. Shrestha DM. Development of mental health services in Nepal. Journal of the Nepalese Medical Association. 23:1. 247-56.

5. Wright C. Community mental health servicesearly experiences: 1988: Proceedings of workshop on National Mental Health Planning; 1987 Dec 30 - 1988 Jan 1; Kathmandu, Nepal;1988.

6. Shrestha DM, Pach A, Rimal KP. A social and psychiatric study of mental illness in Nepal. Kathmandu, Nepal: United Nations Childrens Fund; 1983.

7. Regmi SK, Khalid A, Nepal MK: Challenges of mental health in Nepal. 1999: Souvenir of the Second International Conference of the Psychiatrists Association of Nepal; 1-5. 